\title{
Review
}

\section{Are isothiocyanates potential anti-cancer drugs?}

\author{
Xiang WU, Qing-hua ZHOU*, Ke XU* \\ Tianjin Key Laboratory of Lung Cancer Metastasis and Tumor Microenviroment, Tianjin Lung Cancer Institute, Tianjin Medical University General Hospi- \\ tal, Tianjin 300052, China
}

Isothiocyanates are naturally occurring small molecules that are formed from glucosinolate precursors of cruciferous vegetables. Many isothiocyanates, both natural and synthetic, display anticarcinogenic activity because they reduce activation of carcinogens and increase their detoxification. Recent studies show that they exhibit anti-tumor activity by affecting multiple pathways including apoptosis, MAPK signaling, oxidative stress, and cell cycle progression. This review summarizes the current knowledge on isothiocyanates and focuses on their role as potential anti-cancer agents.

Keywords: isothiocyanate; chemoprevention; anticarcinogenic; antitumor; apoptosis; cell cycle Acta Pharmacologica Sinica (2009) 30: 501-512; doi: 10.1038/aps.2009.50

\section{Introduction}

Numerous studies support the fact that phytochemicals found in certain food substances protect against cancer. Cruciferous vegetables have been widely accepted as potential diet components that may reduce the risk of cancer $^{[1]}$. Isothiocyanates are abundant in cruciferous vegetables such as broccoli, watercress, Brussels sprouts, cabbage, Japanese radish and cauliflower, and they significantly contribute to the cancer chemopreventive activity of these vegetables. Some isothiocyanates derived from cruciferous vegetables, such as sulforaphane (SFN), phenethyl isothiocyanate (PEITC), and benzyl isothiocyanate (BITC), are highly effective in preventing or reducing the risk of cancer induced by carcinogens in animal models. They also inhibit the growth of various types of cancer cells ${ }^{[2,3]}$. These anti-tumorigenic features of isothiocyanates warrant further investigation.

\section{Biosynthesis and metabolism}

Cruciferous vegetables Vegetables of the Cruciferae family are in the botanical order Capparales, which includes the Brassicas genus. Examples are listed in Table 1. The chemopreventative effect of cruciferous vegetables is thought to be partially due to their relatively high content of glu-

* Correspondence to Prof Qing-hua ZHOU and Prof Ke XU. E-mail zhouqh1016@yahoo.com.cn and ke_xu@hotmail.com Received 2009-01-13 Accepted 2009-03-26
Table 1. Vegetables and fruits of the family Cruciferae.

\begin{tabular}{ll}
\hline Genus species (sub species) & Vegetable \\
\hline Armoracia lapathifolia & Horseradish \\
Brassica camoestris (rapifera) & Turnip \\
Brassica camoestris (oleifera) & Rape \\
Brassica napus (napobrassica) & Swede \\
Brassica oleracea (capitata) & White/red cabbage \\
Brassica oleracea (sabauda) & Savoy cabbage \\
Brassica oleracea (gemmifera) & Brussel sprouts \\
Brassica oleracea (cauliflora) & Cauliflower \\
Brassica oleracea (cymosa) & Sprouting broccoli \\
Brassica oleracea (laciniata) & Curly kale \\
Brassica pekinensis & Chinese white cabbage \\
Lepidium sativum & Garden cress \\
Nasturtium officinale & Watercress \\
Raphanus sativus & Radish \\
Sinapis alba & White mustard \\
Carica papaya & Papaya \\
\hline
\end{tabular}

cosinolates ( $\beta$-thioglucoside $N$-hydroxysulfates), which distinguishes them from other vegetables ${ }^{[4]}$. Cruciferous vegetables include the Brassica genus, which includes cabbage, kale, broccoli, cauliflower, Brussels sprouts, kohlrabi, rape, black and brown mustard, and root crops such as turnips and rutabagas (swedes) ${ }^{[s]}$. The glucosinolate content of plants depends on the variety, cultivation, climate and agronomic factors associated with plant growth, and the levels vary between the parts of the specific plant ${ }^{[6]}$; for example, indole glucosinolates are abundant in young shoots and growing 
leaves ${ }^{[7]}$. The chemopreventive activity of glucosinolates is partially mediated by degradation of isothiocyanate derivatives.

Glucosinolates Glucosinolates are substituted $\beta$-thioglucoside $\mathrm{N}$-hydroxysulfates $\mathrm{R}-\mathrm{C}\left(=\mathrm{N}-\mathrm{O}-\mathrm{SO}_{3}{ }^{-}\right)-\mathrm{S}$ glucose. They all contain the $\beta$ - $D$-thioglucose group, a sulfonated oxime moiety, and a variable side chain $\mathrm{R}$. They are hydrolyzed to an aglycone $\mathrm{R}-\mathrm{C}(-\mathrm{SH})=\mathrm{N}-\mathrm{O}-\mathrm{SO}_{3}{ }^{-}$by the enzyme myrosinase (thioglucoside glycohydrolase, EC 3.2.3.1). The thioglycosidic bond is hydrolyzed, glucose is released and an unstable aglycone is formed (Figure 1). The aglycone fragments eliminate sulfate $\mathrm{SO}_{4}{ }^{2-}$ and form isothiocyanate $\mathrm{R}-\mathrm{N}=\mathrm{C}=\mathrm{S}$. Indolyl isothiocyanates undergo a different degradation reaction, because they eliminate $\mathrm{SO}_{4}{ }^{2-}$ and form thiocyanates R-S-C $\equiv \mathrm{N}$. All glucosinolates eliminate $\mathrm{SO}_{4}{ }^{2-}$ and hydrogen sulfide $\mathrm{H}_{2} \mathrm{~S}$ and form nitriles $\mathrm{R}-\mathrm{C} \equiv \mathrm{N}$, particularly under reducing conditions (ferrous ions, ascorbate). Some glucosinolates give rise to other products such as epithionitrile and oxazolidine derivatives. The product distribution depends on the glucosinolate, temperature, $\mathrm{pH}$ and presence of reducing agents. Over 100 different glucosinolates have been identified, and they are classified into 4 groups: saturated aliphatic, unsaturated aliphatic, aromatic and indoly ${ }^{[8]}$. The identities and amount of glucosinolate in plants vary with species, variety and growing conditions. In Brassica vegetables, there are typically $0.5-28 \mu \mathrm{mol}$ aliphatic/ aromatic glucosinolates per gram dry weight and $0.7-8 \mu \mathrm{mol}$ indolyl glucosinolates per gram dry weight. Glucosinolates are normally localized to the cytoplasm of plant tissue ${ }^{[9]}$. Myrosinase is expressed on the external surface of the plant cell wall, so it cannot access the glucosinolates ${ }^{[9]}$. When the tissue is ruptured by chewing, preparation for cooking, heating, or insect attack, myrosinase interacts with the released glucosinolates and hydrolysis products are formed. The myrosinase acting on the glucosinolates may also originate from other species. Most of the dietary isothiocyanate absorbed by mammals from ingested plant material is formed by the action of myrosinase originating from the gastrointestinal tract bacteria ${ }^{[9]}$.

Isothiocyanate Dietary isothiocyanates are formed by the hydrolysis of glucosinolates of ingested cruciferous vegetables (Figure 1). An isothiocyanate is a compound with the structure $\mathrm{R}-\mathrm{N}=\mathrm{C}=\mathrm{S}$, where $\mathrm{R}$ is an alkyl or aryl group. Isothiocyanates are reactive compounds, particularly with respect to nucleophilic attack at the electron-deficient central carbon atom. Nucleophilic attack of isothiocyanates by thiols forms dithiocarbamates R-N(=S)-SR'. These compounds are unstable under physiological conditions and undergo a reverse reaction, which results in the establishment of an equilibrium:

$\mathrm{R}-\mathrm{N}=\mathrm{C}=\mathrm{S}+\mathrm{R}^{\prime} \mathrm{SH} \rightleftharpoons \mathrm{RNHC}(=\mathrm{S})-\mathrm{SR}^{\prime}$

$S$-( $\mathrm{N}$-aralkylthiocarbamoyl)cysteine derivatives are formed from the reaction with cysteinyl thiols. Nucleophilic attack of isothiocyanates by amino groups forms thiourea derivatives with the structure RNH-C(=S)-NHR'. Nucleophilic attack of isothiocyanates by hydroxide ion forms monothiocarbamate derivatives of the form $\mathrm{RNH}-\mathrm{C}(=\mathrm{S})-\mathrm{O}^{-}$. These compounds eliminate carbonyl sulfide COS, which produces the corresponding amine derivative $\mathrm{RNH}_{2}$. These two sequential reactions constitute the irreversible hydrolysis of isothiocyanates that is associated with the loss of pharmacological activity. These are spontaneous reactions that occur under physiological conditions. They initially deliver a $\mathrm{RNH}-\mathrm{C}(=\mathrm{S})$-group to the nucleophile; hence, the reaction is called thiocarbamoylation (Figure 2).

Significant losses of isothiocyanates are expected during

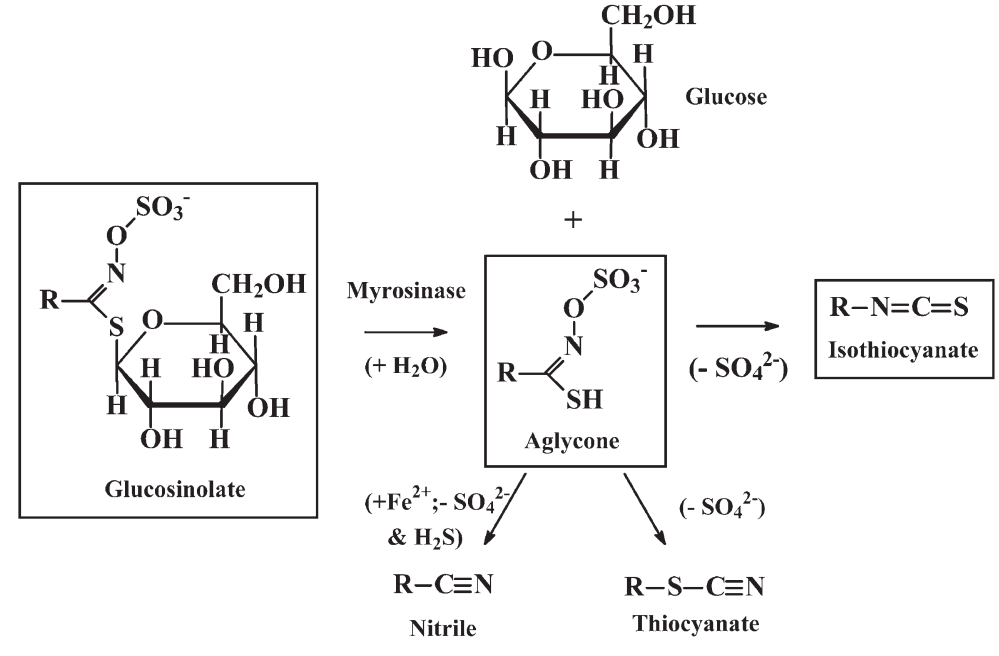

Figure 1. Hydrolysis of glucosinolates by myrosinase and formation of isothiocyanates. 


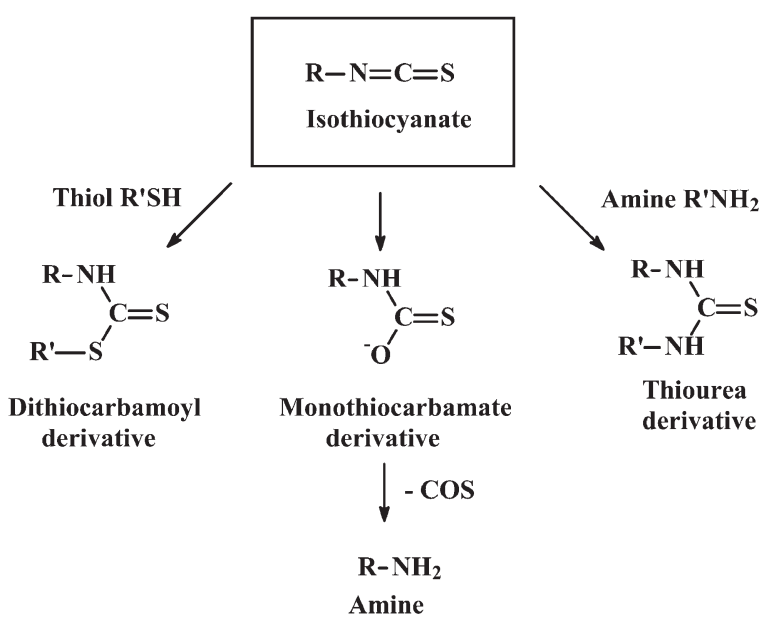

Figure 2. Thiocarbamoylation of isothiocyanates.

food processing. Some isothiocyanates are volatile and will be lost to the atmosphere by vaporization at the boiling point and evaporation at temperatures below the boiling point; for example, loss of allyl isothiocyanate occurs at a boiling point of $88{ }^{\circ} \mathrm{C}$. Isothiocyanates also are hydrolyzed at physiological temperatures (discussed below), a process that becomes more rapid at higher cooking temperatures ${ }^{[10]}$. This is probably due to isothiocyanate volatility and susceptibility to hydrolysis, and it explains why ingested cooked vegetable material often has a very low content of isothiocyanate and a much higher $(>100$ fold $)$ content of glucosinolates ${ }^{[10]}$.

Metabolism of isothiocyanates Once isothiocyanates are ingested or formed in the lumen of the gastrointestinal tract, they cross the gastrointestinal epithelium and the capillary endothelium by passive diffusion. They bind rapidly and reversibly to thiols of plasma protein (approximately 500 $\mu \mathrm{mol} / \mathrm{L}$ ) and cross the plasma membrane into cells of tissues. Inside cells, isothiocyanates react with glutathione to form the glutathione conjugate, $S$-(N-alkyl/arylthiocarbamoyl) glutathione, which is catalyzed by glutathione $S$-transferases (GSTs). The glutathione conjugate is expelled from cells by transporter proteins, also called multidrug resistance proteins (MRPs). In the extracellular medium, the glutathione conjugate $\gamma$-glutamyl and glycyl residues are successively cleaved by $\gamma$-glutamyl transferase $(\gamma$-GT) and dipeptidase, respectively. Both of these enzymes are localized to the extracellular surface of the plasma membrane. The resulting cysteine conjugate is transported to the liver, where $\mathrm{N}$-acetyl transferases acetylate it to form the $N_{\alpha}$-acetyl derivative or mercapturic acid. These are transported to the kidney and are actively secreted into the urine to eliminate them from the body. This mechanism is the mercapturic acid pathway of isothiocyanate metabolism (Figure 3). Mercapturic acid derivatives of dietary isothiocyanates have been detected as major urinary metabolites in rats and human subjects after consumption of glucosinolates ${ }^{[11,12]}$.
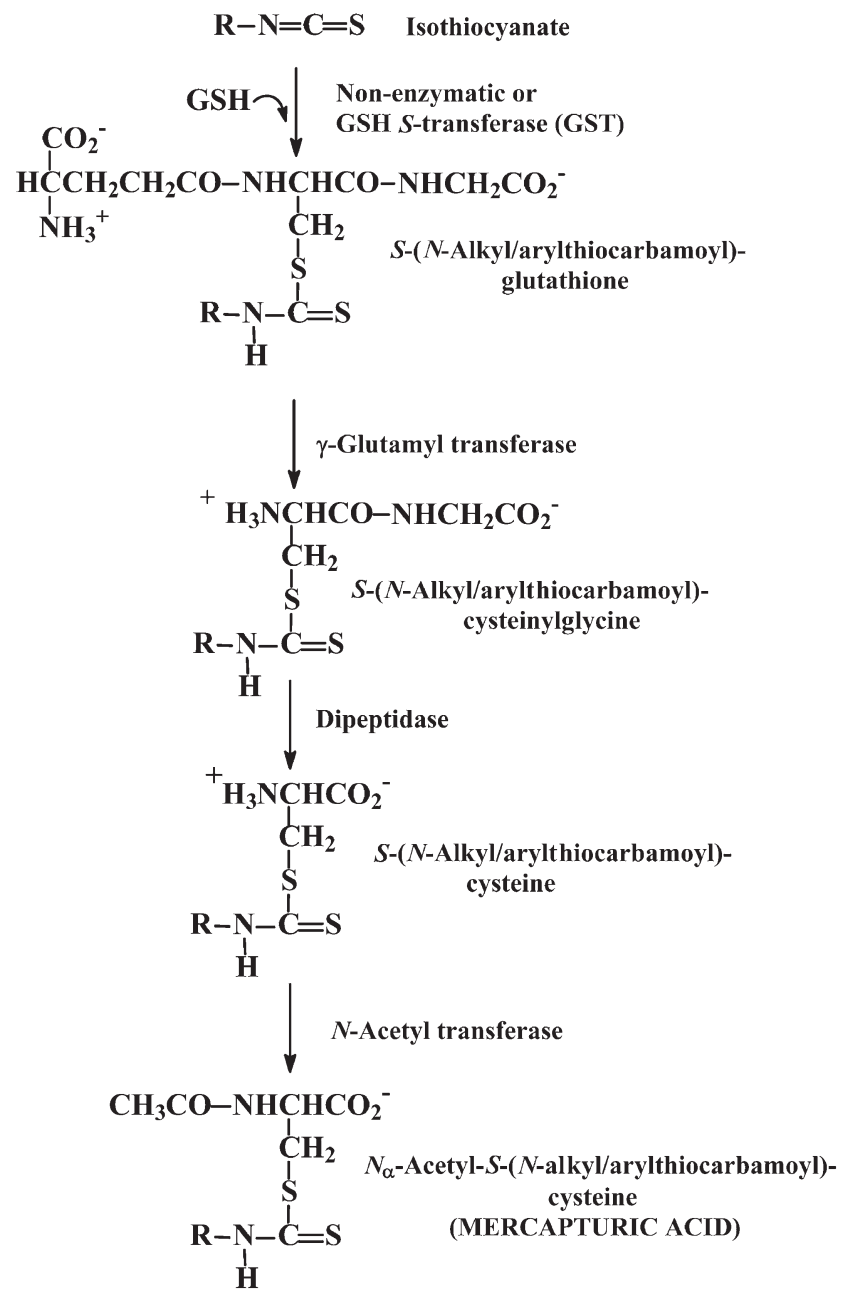

Figure 3. Metabolism of isothiocyanates by the mercapturic acid pathway. $\mathrm{R}$ : is the aliphatic or aromatic substituent of the isothiocyanate.

\section{Anticarcinogenic activity}

Experimental tumorigenesis in laboratory animals The capacity of organic isothiocyanates to block chemical carcinogenesis was first recognized more than 30 years ago with $\alpha$-naphthyl isothiocyanate ${ }^{[13]}$. Since then, approximately 20 natural and synthetic isothiocyanates have been shown to inhibit chemically induced carcinogenesis. The anticarcinogenic activities of isothiocyanates have been demonstrated in rodent models using a wide variety of chemical 
carcinogens, including polycyclic aromatic hydrocarbons, azo dyes, ethionine, fluorenyl acetamide and several nitrosamines. Protection is conferred to a variety of target organs including the lungs, liver, forestomach, mammary gland, esophagus, small intestine, colon and bladder ${ }^{[13,14]}$ (Table 2).

Table 2. Protection against chemical carcinogenesis in rat and mouse organs by isothiocyanates.

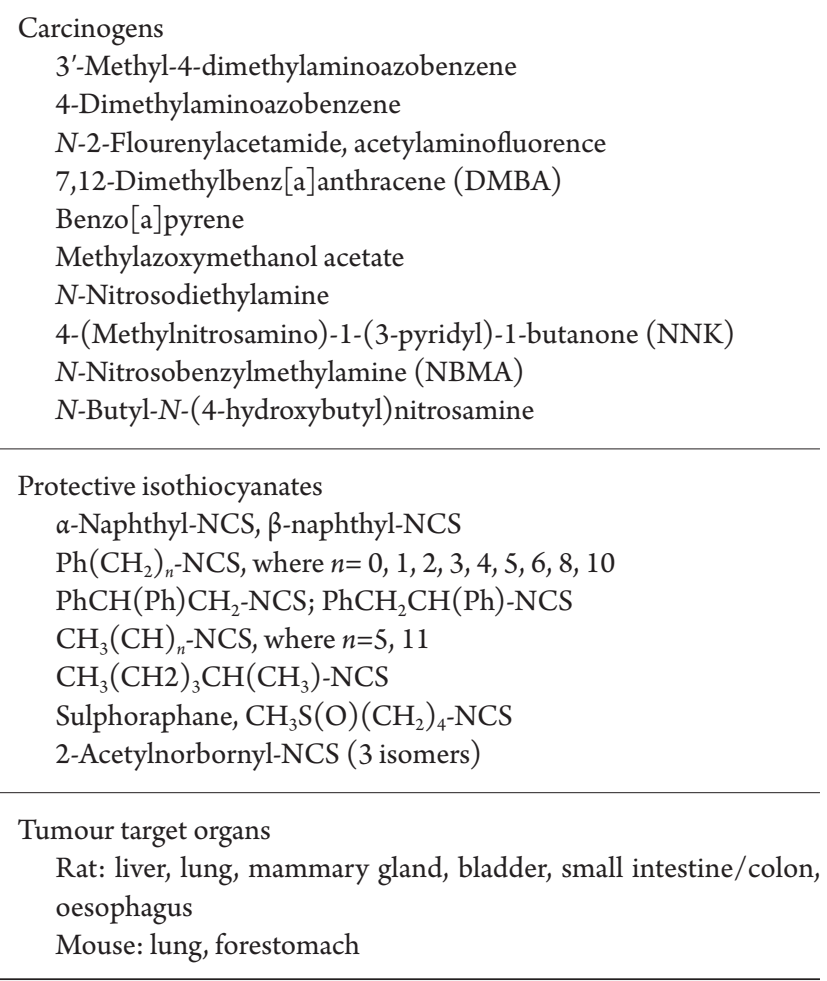

Isothiocyanates inhibited 7,12-dimethylbenz[a]-anthracene (DMBA)-induced mammary tumor formation in female Sprague-Dawley rats when administered $4 \mathrm{~h}$ prior to DMBA administration. Addition of isothiocyanates to a diet containing DMBA also inhibited the formation of forestomach neoplasms and pulmonary adenomas in female ICR/ HA mice. Addition of BITC to the diet containing benz(a) pyrene prevented carcinogenesis in mouse forestomach ${ }^{[15,16]}$.

PEITC, BITC and phenyl isothiocyanate (PITC) were tested for their abilities to inhibit lung tumorigenesis and $\mathrm{O}^{6}$-methylguanine formation (DNA-adduct formation in the 4-(methylnitrosamino)-1-(3-pyridyl)-1-butanone (NNK)induced tumors) in the DNA of lung cells from $\mathrm{A} / \mathrm{J}$ mice treated with $\mathrm{NNK}^{[17-20]}$. $\mathrm{NNK}$ is the most potent tobaccospecific tumorigenic nitrosamine known to induce lung tumors, and it is thought to be associated with the induction of lung cancer in smokers ${ }^{[19]}$. Pretreatment of mice with
PEITC for $96 \mathrm{~h}$ at daily doses of 5 or $25 \mu \mathrm{mol}$ inhibited lung tumor multiplicity induced by a single $10 \mu \mathrm{mol}$ dose of NNK by approximately $70 \%$ or $97 \%$, respectively. PEITC ( $25 \mu \mathrm{mol}$ daily) also decreased the percentage of mice that developed tumors by $70 \%$. In contrast, both BITC and PITC failed to decrease tumor multiplicity or the percentage of mice that developed tumors. However, BITC combined with PEITC decreased tumor multiplicity ${ }^{[21]}$. Similar relative effectiveness was found for isothiocyanates on inducing $\mathrm{O}^{6}$-methylguanine formation in the lungs after NNK administration. Single administration of PEITC ( 5 or $25 \mu \mathrm{mol}$ ) inhibited NNK metabolism by $90 \%$, DNA adduct formation and tumorigenesis in F344 rats ${ }^{[22]}$. However, NNK-induced liver and nasal cavity tumors in rats were not affected by this dietary treatment. The in vivo effect of PEITC on NNK metabolism indicated that PEITC decreased NNK metabolic activation of methylating and pyridyloxobutylating electrophiles in almost all rat tissues examined ${ }^{[23-25]}$.

PEITC also inhibited $\mathrm{N}$-nitrosomethylbenzylamine (NMBA)-induced esophageal tumorigenesis and DNA methylation in rats ${ }^{[17]}$. At doses of $0.75,1.5$, and $3 \mu \mathrm{mol} / \mathrm{kg}$, it inhibited NMBA-induced esophageal tumor multiplicity by $39 \%, 70 \%$, and $100 \%$, respectively. Esophageal tumor incidence was decreased by $0,40 \%$, and $100 \%$, respectively. PEITC exhibited a 53\%-97\% dose-dependent inhibition of the binding of NMBA metabolites to DNA and the levels of DNA methylation at the $\mathrm{N}^{7}(20 \%-89 \%)$ and $\mathrm{O}^{6}(55 \%-93 \%)$ positions of guanine. It also decreased the NBMA metabolism in esophageal tissues, as indicated by the increased levels of unmetabolized NMBA in the medium of cultures containing PEITC ${ }^{[26]}$.

The length of the alkyl chain of the phenylalkyl moiety of isothiocyanate affected the inhibitory potency: the inhibition of tumorigenesis increased as the alkyl chain was increased from 1 to 6 methylene groups. Phenylhexyl isothiocyanate (PHITC) was approximately 50-100 times more potent than PEITC (Table 3) ${ }^{[18]}$. At longer alkyl chain lengths $\left(\mathrm{C}_{8}-\mathrm{C}_{10}\right)$, the inhibitory potency declined ${ }^{[27]}$.

Most isothiocyanates have exhibited chemoprotective activity in protocols involving administration of the isothiocyanate either before or during exposure to the carcinogen. Only BITC inhibited DMBA-induced mammary tumor development when administered to rats after a single dose of DMBA $^{[28]}$.

The protective action of isothiocyanates depends upon many factors: the test system, the target tissue, the type of carcinogen challenge, the isothiocyanates, the dose, and the dosing regimen. For example, PHITC was very potent in blocking NNK-induced lung carcinogenesis in $\mathrm{A} / \mathrm{J}$ mice, but 
Table 3. Effects of arylalkyl isothiocyanates of different chain length on the production of pulmonary tumours in $\mathrm{A} / \mathrm{J}$ mice by 4-(methylnitrosamino)-1-(3-pyridyl)-butanone (NNK).

\begin{tabular}{rlrc}
\hline Group & \multicolumn{1}{c}{ Treatment } & $\begin{array}{c}\text { Tumour } \\
\text { multiplicity } \\
\text { inhibition }\end{array}$ & $\begin{array}{c}\text { Tumour } \\
\text { incidence } \\
\text { inhibition }\end{array}$ \\
\hline 1 & Corn oil/saline & $10 \%$ & $0.1 \pm 0.1$ \\
2 & Corn oil/NNK & $100 \%$ & $7.9 \pm 0.4$ \\
3 & $5 \mu \mathrm{mol} / \mathrm{d}$ PEITC/NNK & $93 \%$ & $4.1 \pm 0.8$ \\
4 & $1 \mu \mathrm{mol} / \mathrm{d}$ PEITC/NNK & $100 \%$ & $6.5 \pm 1.4$ \\
5 & $0.2 \mu \mathrm{mol} / \mathrm{d}$ PEITC/NNK & $100 \%$ & $9.9 \pm 0.8$ \\
6 & $5 \mu \mathrm{mol} / \mathrm{d}$ PPITC/NNK & $11 \%$ & $0.2 \pm 0.1$ \\
7 & $1 \mu \mathrm{mol} / \mathrm{d}$ PPITC/NNK & $75 \%$ & $1.2 \pm 0.3$ \\
8 & $0.2 \mu \mathrm{mol} / \mathrm{d}$ PPITC/NNK & $90 \%$ & $3.7 \pm 0.6$ \\
9 & $5 \mu \mathrm{mol} / \mathrm{d}$ PBITC/NNK & $11 \%$ & $0.2 \pm 0.1$ \\
10 & $1 \mu \mathrm{mol} / \mathrm{d}$ PBITC/NNK & $42 \%$ & $0.8 \pm 0.3$ \\
11 & $0.2 \mu \mathrm{mol} / \mathrm{d}$ PBITC/NNK & $100 \%$ & $4.2 \pm 0.6$ \\
12 & $5 \mu \mathrm{mol} / \mathrm{d}$ PPeITC/NNK & $25 \%$ & $0.3 \pm 0.1$ \\
13 & $1 \mu \mathrm{mol} / \mathrm{d}$ PPeITC/NNK & $53 \%$ & $0.9 \pm 0.3$ \\
14 & $0.2 \mu \mathrm{mol} / \mathrm{d}$ PPeITC/NNK & $100 \%$ & $3.0 \pm 0.4$ \\
15 & $5 \mu \mathrm{mol} / \mathrm{d}$ PHITC/NNK & $5 \%$ & $0.1 \pm 0.1$ \\
16 & $5 \mu \mathrm{mol} / \mathrm{d}$ PHITC/NNK & $0 \%$ & $0.0 \pm 0.0$ \\
17 & $0.2 \mu \mathrm{mol} / \mathrm{d}$ PHITC/NNK & $70 \%$ & $1.2 \pm 0.3$ \\
\hline
\end{tabular}

PEITC: phenethyl isothiocyanate; PPITC: 3-phenylpropyl isothiocyanate; PBITC: 4-phenylbutyl isothiocyanate; PPeITC: 5-phenylpentyl isothiocyanate; PHITC: 6-phenylhexyl isothiocyanate; NNK: 4-(Methylnitrosamino)-1-(3-pyridyl)-1-butanone.

it did not prevent NNK-induced skin tumor formation in the same strains of mice ${ }^{[18]}$. In addition, PHITC enhanced azoxymethane-induced colon tumorigenesis and NMBAinduced esophageal carcinogenesis in rats ${ }^{[29-31]}$. This study demonstrated that the effects of PHITC on esophageal cell proliferation, esophageal metabolism and DNA repair did not account for the enhancement of NMBA-induced tumorigenicity by PHITC, and the mechanism mediating the enhanced tumorigenicity has not been elucidated. Therefore, we should be cautious when we use it as a cancer preventive agent.

Clinical studies There are a limited number of studies that evaluate the effects of isothiocyanates in human subjects. One study involved 11 smokers who avoided cruciferous vegetables and other sources of isothiocyanates ${ }^{[32]}$. They donated 24-h urine samples on 3 consecutive days (baseline period). After 1 to 3 days, they began a watercress consumption period in which they consumed $56.8 \mathrm{~g}$ of watercress at each meal for 3 days and donated 24-h urine samples each day. After one and two weeks, they donated another 24-h urine sample for 2 to 3 consecutive days (follow-up periods). The samples were analyzed for two metabolites of NNK: 4-(methylnitrosamino)-1-(3-pyridyl)-1-butanol (NNAL) and [4-(methylnitrosamino)-1-(3-pyridyl)but-1-yl]- $\beta$-O$D$-glucosiduronic acid (NNAL-gluc), as well as $\mathrm{N}$-acetyl-S(N-phenethylthiocarbamoyl)-L-cysteine (PEITC-NAC), a metabolite of PEITC. NNAL is formed by reduction of NNK and NNAL-gluc, which is the glucuronate conjugate of NNAL. If oxidative metabolism of NNK is blocked, the level of these metabolites should increase. Minimum exposure to PEITC during the watercress consumption period averaged between 19 and $38 \mathrm{mg}$ per day. Seven of the eleven subjects had increased levels of urinary NNAL and NNALgluc on days 2 and 3 of the watercress consumption period compared with the baseline period. Overall, the increase in urinary NNAL and NNAL-gluc in this period was significant [mean \pm SD, $56.1 \pm 17.9 \mathrm{nmol} / 24 \mathrm{~h}(33.5 \%), P<0.01$ ] Urinary levels of NNAL and NNAL-gluc returned to near baseline levels during the follow-up periods. The percent increase in urinary NNAL and NNAL-gluc during days 2 and 3 of the watercress consumption period correlated with PEITC intake during this period as measured by total urinary PEITC-NAC. The results of this study support the hypothesis that PEITC inhibited the oxidative metabolism of NNK in humans, similarly to rodents, and there should be further development of PEITC and other compounds as chemopreventive agents against lung cancer ${ }^{[33]}$.

In order to directly measure the total isothiocyanate levels in human plasma, a high performance liquid chromatography (HPLC)-based method was developed by Liebes et $a l^{[34]}$. This assay utilizes the cyclocondensation reaction of 1,2-benzenedithiol with isothiocyanates present in human plasma, followed by a two-step hexane extraction and analysis by HPLC using UV detection at $365 \mathrm{~nm}$. The method shows linearity and reproducibility with human plasma over a range of 49-3003 nmol/L of PEITC. A similar degree of linearity was observed with two other biologically occurring conjugates of PEITC: PEITC- $N$-acetylcysteine (PEITCNAC) and PEITC-glutathione (PEITC-GSH). In clinical studies, the PEITC level in a non-dietary-controlled group of 23 subjects was measured, and the concentration of PEITC was $413 \pm 193 \mathrm{nmol} / \mathrm{L}$.

Multi-day pharmacokinetic analysis of plasma data from 3 subjects taking a single $40 \mathrm{mg}$ dose of PEITC showed a good CV (coefficient of variation) with a range of $16 \%-21 \%$.

\section{Mechanism of anticarcinogenic activity}

Depression of activation of carcinogens Cytochrome P-450 (CYP) enzymes (phase I enzymes) are important for normal metabolic processing of numerous endogenous and exogenous compounds, but they may also activate certain carcinogens. Isothiocyanates are direct and very potent 
inhibitors (both competitively and irreversibly, depending on conditions) of members of the cytochrome P-450 family. Sulforaphane (SFN) has been shown to inhibit the catalytic activity of a number of CYP enzymes, including CYP1A1, $1 \mathrm{~A} 2,2 \mathrm{~B} 1 / 2,2 \mathrm{E} 1$, and $3 \mathrm{~A} 4^{[35]}$. In a detailed correlative comparison of the arylalkyl isothiocyanates and some alkyl isothiocyanates, Jiao and co-workers ${ }^{[36]}$ found that:

(a) increased alkyl chain length ( $\mathrm{Ph}-\left[\mathrm{CH}_{2}\right]_{n}-\mathrm{NCS}, n=0-6$, $8,10)$ enhanced the inhibitory activity of arylalkyl isothiocyanates against NNK lung tumorigenesis;

(b) the phenyl moiety was not essential for the inhibitory activity, because long-chain alkyl isothiocyanates $\left(\mathrm{eg} \mathrm{\textrm {CH } _ { 3 } -}\right.$ $\left[\mathrm{CH}_{2}\right]_{11}$-NCS) also exhibited strong inhibitory effects in the same model ${ }^{[18,36]}$.

The ability of isothiocyanate to inhibit or enhance tumorigenesis depended on the structure of the isothiocyanates, the animal species, target tissue, and the specific carcinogen employed.

Acceleration of carcinogen disposal The phase 2 enzymes are a diverse family of enzymes that metabolize a variety of reactive carcinogens, mutagens, and other toxins ${ }^{[35]}$. The phase II genes that are induced contain antioxidant (or electrophile) response elements (AREs) in their promoters and include genes encoding $\mathrm{NAD}(\mathrm{P}) \mathrm{H}$ : quinone oxidoreductase (NQO1), GSTs, uridine 5-diphosphate-glucuronosyl transferase (UGT), epoxide hydrolase, ferritin, $\gamma$-glutamatecysteine ligase, and catalase ${ }^{[35]}$.

Isothiocyanates are inducers of phase 2 enzymes. The induction of quinone reductase $(\mathrm{QR})$ and GST activity in various rodent tissues is a characteristic property of isothiocyanates. Aromatic isothiocyanates, $\alpha$ - or $\beta$-naphthyl isothiocyanate, allyl isothiocyanate (AITC), SFN, and exo2-acetyl-exo-6-isothiocyanato-norbornane were shown to be inducers of QR and GST in several bowel, colon, kidney, stomach, lung and nasal mucosa. These compounds were administered either in the diet (3-4 $\mu \mathrm{mol} / \mathrm{g}$ of diet) for $5-28$ days or by intragastric administration $(5-100 \mu \mathrm{mol}$ in single or several daily doses), and the specific activities of GST and QR in the cytosol of these organ were increased by 1.2- to 9.4-fold over those of control animals ${ }^{[13]}$. The coordinated nature of induction of phase 2 enzymes was studied in detailed in Wistar rats with BITC. BITC $(0.5 \%(w / w)$ in the diet for 2 weeks) increased liver and small intestinal GST, $\mathrm{QR}$ and UDP-glucuronyl transferase activities by $1.7-$ to 11 -fold ${ }^{[37]}$. BITC also increased GSH levels in the esophagus and small bowel of ICR/Ha mice by $63 \%-75 \%{ }^{[38]}$. Thus, similar to many chemically unrelated inducers, administration of isothiocyanate to rodents evoked the 'electrophile counter-attack' response. Molecular studies have shown that isothiocyanates can induce phase 2 enzymes by stimulating transcription of phase II genes via a common antioxidant/ electrophile enhancer element (ARE/EpRE) present in the upstream regions of several phase 2 enzyme genes ${ }^{[39]}$.

\section{Antitumor activity}

Aralkyl isothiocyanates have been established to exhibit antiproliferative activities against fungi and bacteria, particularly gram-positive bacteria ${ }^{[40-42]}$. Recently, they have been implicated in mediating antitumor activities. These compounds have inhibitory effects on the growth of several types of cultured cancer cells, including leukemia ${ }^{[43,44]}$, prostate cancer ${ }^{[45]}$, breast cancer ${ }^{[46]}$, lung cancer ${ }^{[47,48]}$, cervical cancer $^{[49]}$, and colorectal cancer ${ }^{[50]}$.

PEITC, AITC and their cysteine conjugates inhibited the in vitro growth and induced the apoptosis of human leukemia HL-60 (p53+) and myeloblastic leukemia-1 cells (p53-) ${ }^{[44]}$. The median growth inhibitory concentration $\left(\mathrm{GC}_{50}\right)$ values were between 1.49 and $3.22 \mu \mathrm{mol} / \mathrm{L}$ in cultures exposed to $10 \%$ serum. Isothiocyanates and cysteine conjugates exhibited increased potency against HL-60 cells in serum-free medium, with $\mathrm{GC}_{50}$ values ranging from $0.8-0.9 \mu \mathrm{mol} / \mathrm{L}$. The potency of the compounds decreased with increased serum content of the medium, but the potency of cysteine conjugates decreased more markedly. Growth inhibition and toxicity were associated with either a rapid interaction of the isothiocyanate with the cells during the first hour of culture or exposure to isothiocyanate liberated from the cysteine conjugate during the initial $3 \mathrm{~h}$ of culture. The inhibition of macromolecule (DNA, RNA, and protein) synthesis and a commitment to apoptosis developed within the initial $24 \mathrm{~h}$ following treatment. PEITC exhibited low toxicity to corresponding differentiated cells, such as neutrophils, in culture. Therefore, the cytotoxicity was selective against leukemia cells $^{[51]}$.

Kuang et al reported that PEITC and BITC inhibited the growth of human non-small cell lung carcinoma A549 cells ${ }^{[47]}$. Their results indicated that both PEITC and BITC inhibited the growth of A549 cells in a dose-dependent manner. Flow cytometric analyses and annexin $\mathrm{V}$ staining showed that apoptosis occurred at low concentrations of PEITC and BITC $(\leq 10 \mu \mathrm{mol} / \mathrm{L})$, and necrosis occurred at higher concentrations of PEITC and BITC $(25 \mu \mathrm{mol} / \mathrm{L})$.

Mechanism of antitumor activity The mechanism for the antitumor activity of isothiocyanates has not been fully elucidated; however, studies have implicated numerous pathways (Figure 4).

Induction of apoptosis The induction of apoptosis by 


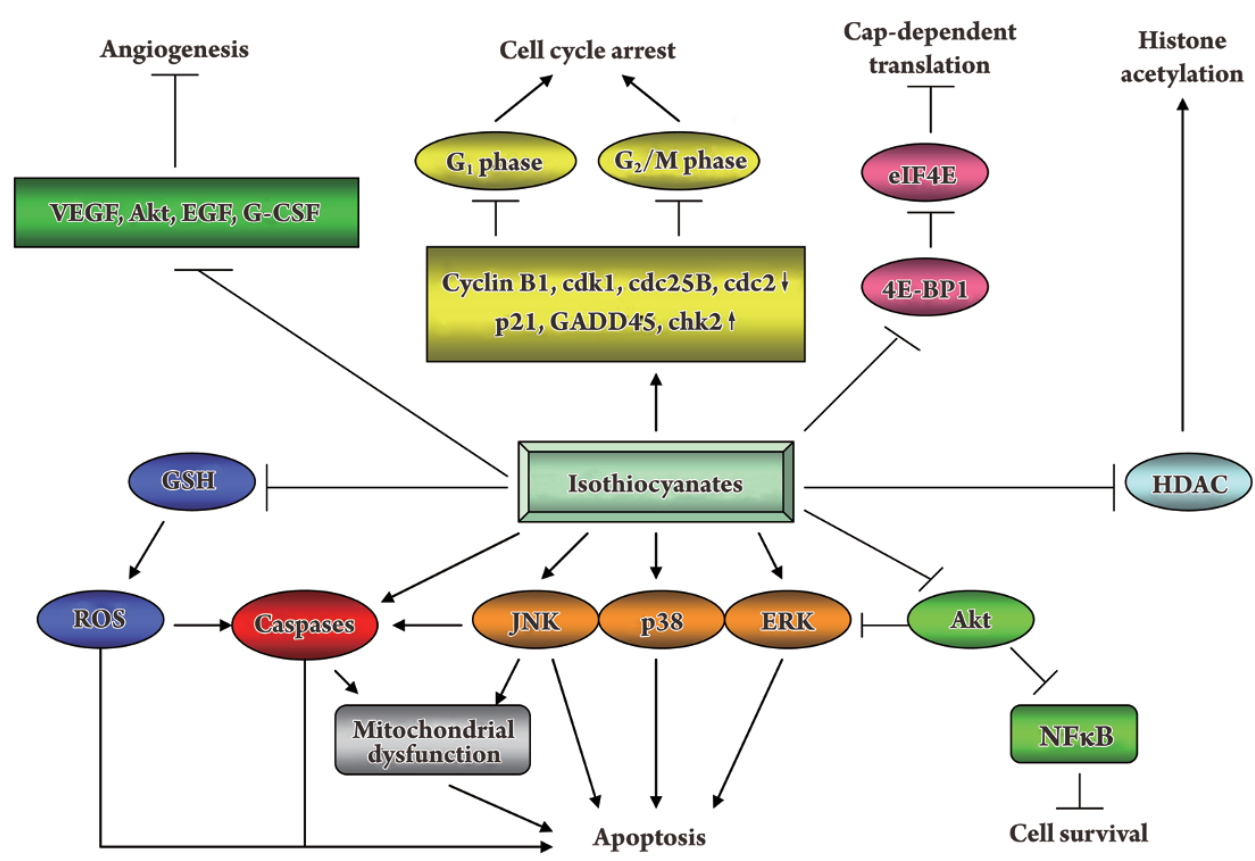

Figure 4. Schematic pathways of the antitumor activity of isothiocyanates. isothiocyanates was first documented by Yu et al in $1998^{[52]}$. Their study showed that PEITC and other structurally related isothiocyanates, phenylmethyl isothiocyanate, phenylbutyl isothiocyanate, and phenylhexyl isothiocyanate, but not phenyl isothiocyanate, induced apoptosis in HeLa cells in a time- and dose-dependent manner. In addition, treatment with apoptosis-inducing concentrations of isothiocyanates caused rapid and transient induction of caspase-3/CPP32like activity. Furthermore, these isothiocyanates, except phenyl isothiocyanate, stimulated proteolytic cleavage of poly-(ADP-ribose) polymerase, which followed the caspase activation and preceded DNA fragmentation. Pretreatment with a potent caspase-3 inhibitor AC-DEVD-CHO inhibited isothiocyanate-induced caspase- 3 activation and apoptosis. These results suggest that isothiocyanates induce apoptosis through a caspase-3-dependent mechanism.

PEITC and AITC inhibit leukemia cell growth by inducing apoptosis. Activities of caspase- 3 and caspase- 8 were increased during isothiocyanate-induced apoptosis, but caspase- 1 activity was not. The general caspase inhibitor Z-VAD-fmk and the specific caspase-8 inhibitor Z-IETDfmk inhibited apoptosis, but specific caspase- 1 and caspase- 3 inhibitors did not. This suggests that caspase- 8 is critical and caspase-3 may exert a supporting role during apoptosis in leukemia cells ${ }^{[43]}$. Apoptosis was associated with cleavage of $\mathrm{p} 22$ BID protein to $\mathrm{p} 15, \mathrm{p} 13$, and $\mathrm{p} 11$ fragments, activation of JNK, and tyrosine phosphorylation. This suggests that during isothiocyanate-induced human leukemia, cell apop- tosis depends on the caspase pathway, and the JNK pathway may play a supporting role ${ }^{[44]}$.

SFN induced prostate cancer cell apoptosis, by activation of caspases, ERK1/2, and Akt, and increasing p53 and bax protein levels. Apoptosis induction was also observed in medulloblastoma and human pancreatic cancer cells. Recent results demonstrated the ability of SFN to induce apoptosis in glioblastoma cell lines through the activation of multiple molecular mechanisms ${ }^{[53]}$.

The mitochondria are involved in the apoptosis induced by isothiocyanates. PEITC induced apoptosis in HT-29 human colorectal carcinoma cells ${ }^{[50]}$. Both caspase-3 and -9 activities were stimulated by PEITC. The release of cytochrome $c$ from the mitochondrial inter-space was time- and dose-dependent, with a maximal release at $50 \mu \mathrm{mol} / \mathrm{L}$ after $10 \mathrm{~h}$ of treatment.

MAPK pathway Three MAPKs [JNK (c-Jun N-terminal kinase), extracellular signal-regulated protein kinase (ERK) and p38 kinase] were activated shortly after PEITC treatment in HT-29 cells. The JNK inhibitor SP600125, but not the ERK and p38 inhibitors, suppressed PEITC-induced apoptosis. Similarly, this JNK inhibitor attenuated both cytochrome $c$ release and caspase- 3 activation induced by PEITC, suggesting that activation of JNK is critical for the initiation of apoptosis ${ }^{[50]}$.

In ovarian cancer OVCAR-3 cells, PEITC suppressed the activation of Akt and ERK1/2 while simultaneously activating pro-apoptotic p38 and JNK1/2. Specific inhibi- 
tors of JNK1/2 and p38 reversed the cytotoxic effect of PEITC. These findings suggest that PEITC inhibits Akt- and ERK1/2-mediated survival signaling while simultaneously activating pro-apoptotic $\mathrm{p} 38$ and JNK1/2 signaling ${ }^{[54]}$.

$\mathrm{Xu}$ et al investigated the regulation of activator protein 1 (AP-1) by ERK and JNK signaling pathways, and they investigated human prostate cancer PC-3 cell death induced by three isothiocyanates ${ }^{[45]}$. SFN, PEITC, and AITC each potently induced AP-1 activity and caused a significant elevation in the phosphorylation of ERK1/2, JNK1/2, Elk-1, and c-Jun. Transfection with ERK2 and the upstream kinase DNEE-MEK1 activated AP-1 activity, and transfection with the dominant-negative mutant ERK2 (dnERK2) potently decreased AP-1 activation induced by SFN, PEITC and AITC. Transfection with JNK1 and upstream kinase MKK7 activated AP-1 activity, and transfection with dominantnegative mutant JNK1-APF significantly attenuated AP-1 activation induced by SFN, PEITC, and AITC. Pretreatment with the MEK1-ERK inhibitor U0126 and the JNK inhibitor SP600125 substantially attenuated the decrease in cell viability induced by SFN, PEITC, and AITC. Transfection with dnERK2 and JNK1-APF significantly reversed the decrease in Bcl-2 expression elicited by these isothiocyanates. Furthermore, transfection with dnERK2 and JNK1-APF blocked the apoptosis induced by these isothiocyanates in PC-3 cells. Taken together, these results indicate that the activation of the ERK and JNK signaling pathways is important for AP-1 transcriptional activity and is involved in the regulation of cell death elicited by isothiocyanates in PC-3 cells.

Oxidative stress Reactive oxygen species (ROS) stimulate cell proliferation and induce genetic instability, and their increased level in cancer cells is often viewed as an adverse event. Abnormal increases in ROS can be exploited to selectively kill cancer cells. Oncogenic transformation of ovarian epithelial cells with $\mathrm{H}-\mathrm{RaS}{ }^{\mathrm{V} 12}$ or expression of $\mathrm{Bcr}-\mathrm{Abl}$ in hematopoietic cells caused elevated ROS generation and rendered the malignant cells highly sensitive to PEITC. PEITC effectively disables the glutathione (GSH) antioxidant system and causes ROS accumulation preferentially in the transformed cells due to their active ROS output. Excessive ROS cause oxidative mitochondrial damage, cytochrome $c$ release, inactivation of redox-sensitive molecules (GXP), and massive cell death ${ }^{[55]}$.

Oxidative stress caused by isothiocyanates can be used to treat drug-resistant cancer cells. Chronic lymphocytic leukemia (CLL) is the most common adult leukemia, and resistance to fludarabine-based therapies is a major challenge in CLL treatment. Because CLL cells have elevated levels of reactive oxygen species (ROS), Trachootham et al tested a novel ROS-mediated strategy to eliminate fludarabineresistant CLL cells based on this redox alteration. Using primary CLL cells and normal lymphocytes from patients and healthy individuals, they found that both fludarabineresistant and -sensitive CLL cells were highly sensitive to PEITC, exhibiting mean $\mathrm{IC}_{50}$ values of 5.4 and $5.1 \mu \mathrm{mol} / \mathrm{L}$, respectively. Normal lymphocytes were significantly less sensitive to PEITC $\left(\mathrm{IC}_{50}=27 \mu \mathrm{mol} / \mathrm{L}, P<0.0001\right)$. CLL cells exhibited intrinsically higher ROS levels and lower cellular GSH, which were shown to be the critical determinants of CLL sensitivity to PEITC. Exposure of CLL cells to PEITC induced severe GSH depletion, ROS accumulation, and oxidation of mitochondrial cardiolipin leading to massive cell death. Such ROS stress also caused deglutathionylation and rapid degradation of the cell survival molecule MCL1. This study demonstrated that PEITC was effective in eliminating fludarabine-resistant CLL cells through a redox-mediated mechanism with low toxicity to normal lymphocytes ${ }^{[56]}$.

Isothiocyanates induce cellular oxidative stress by rapidly conjugating and thus depleting cells of GSH in leukemia cells $^{[57]}$. PEITC induced apoptosis of human leukemia HL-60 and myeloblastic leukemia ML-1 cells, which was associated with an initial decrease in GSH and GSSG (oxidized GSH) and concomitant formation of the GSH adduct $S$-(N-phenethylthiocarbamoyl)glutathione inside cells. This adduct was then exported from cells.

Inhibition of cell cycle progression The induction of cell cycle arrest by isothiocyanates was first reported by Hasegawa and coworkers in $1993^{[58]}$. The accumulation of cells at $\mathrm{G}_{2} / \mathrm{M}$ phase was observed $16 \mathrm{~h}$ after treatment with 10 $\mu \mathrm{mol} / \mathrm{L}$ AITC, $2.5 \mu \mathrm{mol} / \mathrm{L}$ BITC or PEITC, the concentrations at which cell growth was inhibited by $41 \%-79 \%$ compared with the control. These results suggest that isothiocyanates delay the cell cycle progression of HeLa cells, resulting in the inhibition of cell growth.

SFN $(20 \mu \mathrm{mol} / \mathrm{L})$ completely inhibited the growth of LM8 cells and caused $\mathrm{G}_{2} / \mathrm{M}$-phase arrest. SFN induced the expression of $\mathrm{p} 21$ (WAF1/CIP1) protein, which caused cell cycle arrest in a dose-dependent manner ${ }^{[59]}$. An additional study showed that SFN inhibited human lung adenocarcinoma LTEP-A2 cell growth by causing $\mathrm{G}_{2} / \mathrm{M}$-phase arrest ${ }^{[60]}$.

Isothiocyanates may induce cell cycle arrest in different phases in a cell line dependent manner. AITC arrested HL- 60 cells at the $G_{1}$ phase, whereas BITC arrested the cells at both the $G_{1}$ and the $G_{2} / M$ phases ${ }^{[61]}$. When AITC induced prostate cancer PC- 3 cell arrest at $G_{2} / M$ phase, cyclin B1 levels were dramatically decreased, as well as cdk1, cdc25B, and cdc25C. This suggested that cyclin B1, cdk1, cdc25B, and cdc25C may be targeted by AITC ${ }^{[62]}$. In HL-60 
cells, BITC significantly up-regulated expression of $\mathrm{G}_{2} / \mathrm{M}$ cell cycle arrest-regulating genes including p21, GADD45, and 14-3-3 sigma ${ }^{[63]}$. A similar result was observed in human Capan-2 pancreatic cancer cells. BITC-mediated $\mathrm{G}_{2} / \mathrm{M}$ arrest was associated with the up-regulation of p21 and the activation of checkpoint kinase 2 (Chk2), whereas the expression of other $\mathrm{G}_{2} / \mathrm{M}$ regulatory proteins, including CyclinB1, Cdc2, and Cdc25C, was down-regulated ${ }^{[64]}$.

Inhibition of angiogenesis Inhibition of angiogenesis may be an important mechanism employed by PEITC to prevent cancer. PEITC treatment decreased the survival of human umbilical vein endothelial cells (HUVEC) in a concentration- and time-dependent manner ${ }^{[65]}$. The formation of a capillary-like tube structure (in vitro neovascularization) by HUVECs and their migration (invasion potential) were also inhibited significantly in the presence of PEITC at pharmacologically relevant concentrations $(<1 \mu \mathrm{mol} / \mathrm{L})$. The PEITC-mediated inhibition of angiogenic features of HUVEC in vitro was associated with suppression of vascular endothelial growth factor (VEGF) secretion, down-regulation of VEGF receptor 2 protein levels, and inactivation of Akt. PEITC treatment reduced the migration of PC-3 human prostate cancer cells, which correlated with inactivation of Akt, suppression of VEGF and epidermal growth factor (EGF) expression, and granulocyte colony-stimulating factor (G-CSF) secretion. The PEITC-mediated inhibition of PC-3 cell migration was significantly attenuated by ectopic expression of constitutively active Akt. More importantly, PEITC treatment inhibited ex vivo angiogenesis as assessed using a chicken egg chorioallantoic membrane assay.

Inhibition of histone deacetylation Isothiocyanates are histone deacetylase inhibitors ${ }^{[66]}$. SFN was first reported to inhibit HDAC activity in human colon cancer cells ${ }^{[67]}$. In human embryonic kidney 293 cells and human colorectal cancer HCT116 cells, SFN dose-dependently increased the activity of a beta-catenin-responsive reporter (TOPflash) without altering beta-catenin or HDAC protein levels. Cytoplasmic and nuclear extracts from these cells had diminished HDAC activity, and global and localized histone acetylation was increased in both cell lines.

The histone deacetylase inhibitory activity was also studied in other cells. SFN treatment significantly inhibited HDAC activity in four breast cancer cell lines: MDA-MB231, MDA-MB-468, MCF-7, and T47, particularly in the ER-negative cell lines, MDA-MB-231, and MDA-MB-468 cells. Despite this significant inhibition in global HDAC activity, no significant changes were observed in the acetylation of $\mathrm{H} 3$ or $\mathrm{H} 4$ in any cell line following $48 \mathrm{~h}$ of exposure to $15 \mu \mathrm{mol} / \mathrm{L}$ sulforaphane ${ }^{[68]}$.
PHITC inhibits the growth of human leukemia HL-60 cells via chromatin remodeling. PHITC reduced the expression of HDAC and increased the levels of acetyl transferase p300, in favor of accumulation of acetylated histones. The global acetylation of histones was enhanced within hours ${ }^{[69]}$.

Regulation of translation initiation $\mathrm{Hu}$ et al reported a novel response of PEITC at pharmacologically relevant concentrations on the regulation of translation initiation ${ }^{[70]}$. Treatment of human colorectal cancer HCT-116 cells and human prostate cancer PC-3 cells, but not a normal prostate epithelial cell line (PrEC), with PEITC caused an increase in expression of the eukaryotic translation initiation factor $4 \mathrm{E}$ (eIF4E) binding protein (4E-BP1) and inhibition of 4E-BP1 phosphorylation. Results from pull-down assays indicated that PEITC treatment reduced cap-bound eIF4E, confirming that increased 4E-BP1 expression and inhibition of 4E-BP1 phosphorylation reduced the availability of eIF4E for translation initiation. Accordingly, results from in vivo translation experiments using a luciferase reporter assay indicated that PEITC treatment inhibited cap-dependent translation, particularly the translation of mRNA with secondary structure (stem-loop structure). Ectopic expression of eIF4E prevented PEITC-induced translation inhibition and conferred significant protection against PEITC-induced apoptosis. These results indicate that PEITC modulates the availability of eIF4E for translation initiation leading to inhibition of cap-dependent translation. This suggests that inhibition of cap-dependent translation may be an important mechanism for PEITC-induced apoptosis.

\section{Conclusion and perspectives}

The emerging evidence from in vitro and in vivo studies over the past 20 years has revealed that isothiocyanates are chemopreventive agents. The ability of isothiocyanate to inhibit tumorigenesis depended on the structure of the isothiocyanates, the animal species, target tissues, and the specific carcinogen employed. Isothiocyanates also exhibit antitumor activity. They target multiple pathways including apoptosis, the MAPK pathway, oxidative stress, and the cell cycle machinery. Apoptosis induced by various isothiocyanates has been extensively studied in cancer cell lines derived from various tissues. The mechanism of these activities is not fully understood. Future research should focus on: a) molecular target screening; b) in-depth mechanistic studies; c) in vivo animal experiments; d) novel clinical trials; and e) novel compound design and development based on isothiocyanate. Moreover, optimization of the isothiocyanate dose and dosing scheme for human study is necessary. 


\section{Acknowledgements}

Research in the authors' laboratory is supported in part by the National Natural Science Foundation of China (№ 30873035) and the Key Project of the Foundation of Tianjin High Education Commission (№ ZD200714).

\section{References}

1 Lam TK, Gallicchio L, Lindsley K, Shiels M, Hammond E, Tao $\mathrm{XG}$, et al. Cruciferous vegetable consumption and lung cancer risk: a systematic review. Cancer Epidemiol Biomarkers Prev 2009; 18: 184-95.

2 Trachootham D, Zhang H, Zhang W, Feng L, Du M, Zhou Y, et al. Effective elimination of fludarabine-resistant CLL cells by PEITC through a redox-mediated mechanism. Blood 2008; 112: 1912-22.

3 Lee JW, Cho MK. Phenethyl isothiocyanate induced apoptosis via down regulation of $\mathrm{Bcl}-2 / \mathrm{XIAP}$ and triggering of the mitochondrial pathway in MCF-7 cells. Arch Pharm Res 2008; 31 : 1604-12.

4 Verhoeven DTH, Goldbohm RA, van Poppel G, Verhagen H, van den Brandt PA. Epidemiological studies on Brassica vegetables and cancer risk. Cancer Epidermiol Biomarkers Prev 1996; 5: 733-48.

5 Verhoeven DTH, Verhagen H, Goldbohm RA, van den Brandt PA, van Poppel G. A review of mechanisms underlying anticarcinogenicity by brassica vegetables. Chem Biol Interact 1997; 103: 79-129.

6 Fenwick GR, Heaney RK, Mullin WJ. Glucosinolates and their breakdown products in food and food plants. Crit Rev Food Sci Nutr 1983; 18: 123-201.

7 McDanell R, McLean AEM. Chemical and biological properties of indole glucosinolates (glucobrassicins): a review. Food Chem Toxicol 1988; 26: 59-70.

8 Mithen R, Dekker M, Verkerk R, Rabot S, Johnson IT. The nutritional significance, biosynthesis and bioavailability of glucosinolates in human foods. J Sci Food Agric 2000; 80: 967-84.

9 Rask L, Andreasson E, Ekbom B, Eriksson S, Pontoppidan B, Meijer J. Myrosinase: gene family evolution and herbivore defence in Brassicaceae. Plant Mol Biol 2000; 42: 93-113.

10 Shapiro T, Fahey JW, Wade K, Stephenson K, Talalay P. Human metabolism and excretion of cancer chemoprotective glucosinolates and isothiocyanates of cruciferous vegetables. Cancer Epidemiol Biomarkers Prev 1998; 7: 1091-100.

11 Chung FL, Jiao D, Getahun SM, Yu MC. A urinary biomarker for uptake of dietary isothiocyanates in humans. Cancer Epidemiol Biomarkers Prev 1998; 7 : 103-8.

12 Mennicke WH, Kral T, Krumbiegel G, Rittmann N. Determination of $N$-acetyl-S-( $N$-alkylthiocarbomoyl)-L-cysteine, a principal metabolite of alkyl isothiocyanates, in rat urine. J Chromatogr Biomed 1987; 414: 19-24.

13 Zhang Y, Talalay P. Anticarcinogenic activities of organic isothiocyanates-chemistry and mechanisms. Cancer Res 1994; 54 (7 Suppl): 1976s-1981s.

14 Hecht SS. Chemoprevention by isothiocyanates. J Cell Biochem (Suppl) 1995; 22: 195-209.

15 Wattenberg LW. Inhibition of carcinogenic effects of polycyclic hydrocarbons by benzyl isothiocyanate and related compounds. J Natl Cancer Inst 1977; 58: 395-8.

16. Wattenberg LW. Inhibition effects of benzyl isothiocyanate administered shortly before diethylnitrosamine or benzo[a] pyrene on pulmonary and forestomach neoplasia in A/J mice. Carcinogenesis 1987; 8: 1971-3.

17 Morse MA, Zu H, Galati AJ, Schmidt CJ, Stoner GD. Doserelated inhibition by dietary phenethyl isothiocyanate of esophageal tumorigenesis and DNA methylation induced by $N$-nitromethylbenzylamine in rats. Cancer Lett 1993; 72: 103-10.

18 Morse MA, Eklind KI, Hecht SS, Jordan KG, Choi C, Desai DH, et al. Structure-activity relationships for inhibition of 4-(methylnitrosamino)-1-(3-pyridyl)-butanone lung tumorigenesis by aralkyl isothiocyanate in A/J mice. Cancer Res 1991; 51: 1846-50.

19 Morse MA, Amin SG, Hecht SS, Chung F. Effects of aromatic isothiocyanates on tumorigenicity, O6-methylguanine formation, and metabolism of the tobacco-specific nitrosamine 4-(methylnitrosamino)-1-(3-pyridyl)-butanone in $\mathrm{A} / \mathrm{J}$ mice lung. Cancer Res 1989; 49: 2894-7.

20 Morse MA, Eklind KI, Amin SG, Hecht SS, Chung F. Effects of alkyl chain length on the inhibition of NNK-induced lung neoplasia in $\mathrm{A} / \mathrm{J}$ mice by aralkyl isothiocyanates. Carcinogenesis 1989; 10: 1757-9.

21 Sticha KRK, Kenney PMJ, Boysen G, Liang H, Su XJ, Wang MY, et al. Effect of benzyl isothiocyanate and phenethyl isothiocyanate on DNA adduct formation by amixture of benzo[a]pyrene and 4-(methylnitrosamino)-1-(3-pyridyl)-1-butanone in A/J mouse lung. Carcinogenesis 2002; 23: 1433-9.

22 Morse MA, Wang C, Stoner GD, Mandal S, Conran PB, Amin $\mathrm{SG}$, et al. Inhibition of 4-(methylnitrosamino)-1-(3-pyridyl)butanone-induced DNA adduct formation and tumorigenicity in the lung of F344 rats by dietary phenylethyl isothiocyanate. Cancer Res 1989; 49: 549-53.

23 Yang CS, Smith TJ, Hong JY. Cytochrome P-450 enzymes as targets for chemoprevention against chemical carcinogenesis and toxicity: opportunities and limitiations. Cancer Res 1994; 54 (7 Suppl): 1982s-1986s.

24 Guo Z, Smith TJ, Wang E, Eklind KI, Chung FL, Yang CS. Structure activity relationships of arylalkyl isothiocyanates for the inhibition of 4-(methylnitrosamino)-1-(3-pyridyl)-butanone metabolism and the modulation of xenobiotic metabolizing enzymes in rats and mice. Carcinogenesis 1993; 14: 1167-73.

25 Boysen G, Kenney PM, Upadhyaya P, Wang M, Hecht SS. Effects of benzyl isothiocyanate and 2-phenethyl isothiocyanate on benzo[a]pyrene and 4-(methylnitrosamino)-1-(3-pyridyl)-1butanone metabolism in F-344 rats. Carcinogenesis 2003; 24 : 517-25.

26 Stoner GD, Morrissey DT, Heur YH, Daniel EM, Galati AJ, Wagner SA. Inhibitory effects of phenethyl isothiocyanate on $\mathrm{N}$ nitrosobenzylmethylamine carcinogenesis in the rat esophagus. Cancer Res 1991; 51: 2063-8.

27 Conaway CC, Jiao D, Chung FL. Inhibition of rat liver cytochrome P450 isozymes by isothiocyanates and their conjugates: a structure-activity relationship study. Carcinogenesis 1996; 16: 2423-7.

28 Wattenberg LW. Inhibition of carcinogen-induced neoplasia by sodium cyanate, tert-butyl isocyanate, and benzyl isothiocyanate adminstered subsequent to carcinogen exposure. Cancer Res 
$1981 ; 41: 2991-4$

29 Rao CV, Rivenson A, Simi B, Zang E, Hamid R, Kelloff GJ, et al. Enhancement of experimental colon carcinogenesis by dietary 6-phenylhexyl isothiocyanate. Cancer Res 1995; 55: 4311-8.

30 Hudson TS, Carlton PS, Gupta A, Stoner GD, Morse MA. Investigation of the enhancement of $\mathrm{N}$-nitrosomethylbenzylamineinduced esophageal tumorigenesis by 6-phenylhexyl isothiocyanate. Cancer Lett 2001; 10: 19-26.

31 Morse MA, Lu J, Gopalakrishnan R, Peterson LA, D'Ambrosio SM, Wani G, et al. Mechanism of enhancement of esophageal tumorigenesis by 6-phenylhexyl isothiocyanate. Cancer Lett 1997; 112: 119-25.

32 Hecht SS, Chung FL, Richie JPJ, Akerkar SA, Skowronski L, Carmella SG. Effects of watercress consumption on metabolism of a tobacco-specific lung carcinogen in smokers. Cancer Epidemiol Biomarkers Prev 1995; 4: 877-84.

33 Hecht SS. Approaches to chemoprevention of lung cancer based on carcinogens in tobacco smoke. Environ Health Perspect 1997; 105 Suppl 4: 955-63.

34 Liebes L, Conaway CC, Hochster H, Mendoza S, Hecht SS, Crowell J, et al. High-performance liquid chromatography-based determination of total isothiocyanate levels in human plasma: application to studies with 2-phenethyk isothiocyanate. Anal Biochem 2001; 291: 279-89.

35 Fimognari C, Lenzi M, Hrelia P. Interaction of the isothiocyanate sulforaphane with drug disposition and metabolism: pharmacological and toxicological implications. Curr Drug Metab 2008; 9: 668-78.

36 Jiao D, Eklind KI, Choi CI, Desai DH, Amin SG, Chung FL. Structure-activity-relationships of isothiocyanates as mechanismbased inhibitors of 4-(methylnitrosamino)-1-(3-pyridyl)-1butanone-induced lung tumorigenesis in $\mathrm{A} / \mathrm{J}$ mice. Cancer Res 1994; 54: 4327-33.

37 Kassie F, Rabot S, Uhl M, Huber W, Qin HM, Helma C, et al. Chemoprotective effects of garden cress (Lepidium sativum) and its constituents towards 2-amino-3-methyl-imidazo[4,5-f] quinoline (IQ)-induced genotoxic effects and colonic preneoplastic lesions. Carcinogenesis. 2002; 23:1155-61

38 Talalay P, Zhang Y. Chemoprevention against cancer by isothiocyanates and glucosinates. Biochem Soc Trans 1996; 24: 806-10.

39 Prawan A, Keum YS, Khor TO, Yu S, Nair S, Li W, et al. Structural influence of isothiocyanates on the antioxidant response element (ARE)-mediated heme oxygenase-1 (HO-1) expression. Pharm Res 2008; 25: 836-44.

40 Dornberger K, Bockel V, Heyer J, Schonfeld CL, Tonew M, Tonew E. Untersuchungen uber die isothiocyanate erysolin und sulphoran an Cardaria draba. L Pharmazie 1975; 30: 1029-34.

41 Virtanen AI, Kreula M, Kievaara M. Investigations on the alleged goitrogenic properties of milk. Z Ernahrungsweiss Suppl 1963; 3: 23-37.

42 Zsolnai T. Die antimikrobielle wirkung von thiocyanates und isothiocyanates. Arnneim Forschung 1997; 16: 870-6.

$43 \mathrm{Xu} \mathrm{K}$, Thornalley PJ. Studies on the mechanism of the inhibition of human leukaemia cell growth by dietary isothiocyanates and their cysteine adducts in vitro. Biochem Pharmacol 2000; 60: 221-31.

$44 \mathrm{Xu} \mathrm{K}$, Thornalley PJ. Signal transduction activated by the cancer chemopreventive isothiocyanates: cleavage of BID protein, tyrosine phosphorylation and activation of JNK. Br J Cancer 2001; 84: 670-3.

45 Xu CJ, Shen GX, Yuan XL, Kim JH, Gopalkrishnan A, Keum YS, et al. ERK and JNK signalling pathways are involved in the regulation of activator protein 1 and cell death elicited by three isothiocyanates in human prostate cancer PC-3 cells. Carcinogenesis 2006; 27: 437-45.

46 Tseng E, Scott-Ramsay EA, Morris ME. Dietary organic isothiocyanates are cytotoxic in human breast cancer MCF-7 and mammary epithelial MCF-12A cell lines. Exp Biol Med 2004; 229: $835-42$.

47 Kuang YF, Chen YH. Induction of apoptosis in a non-small cell human lung cancer cell line by isothiocyanates is associated with p53 and p21. Food Chem Toxicol 2004; 42: 1711-8.

48 Mi LX, Wang XT, Govind S, Hood BL, Veenstra TD, Conrads $\mathrm{TP}$, et al. The role of protein binding in induction of apoptosis by phenethyl isothiocyanate and sulforaphane in human non-small lung cancer cells. Cancer Res 2007; 67: 6409-16.

49 Yu R, Jiao JJ, Duh JL, Tan TH, Kong ANT. Phenethyl isothiocyanate, a natural chemopreventive agent, activates c-Jun N-terminal kinase-1. Cancer Res 1996; 56: 2954-9.

$50 \mathrm{Hu}$ R, Kim BR, Chen C, Hebbar V, Kong ANT. The roles of JNK and apoptosis signalling pathways in PEITC-mediated responses in human HT-29 colon adenocarcinoma cells. Carcinogenesis 2003; 24: 1361-7.

51 Adesida A, Edwards LG, Thornalley PJ. Inhibition of human leukaemia 60 cell growth by $S$-( $N$-phenylethylthiocarbamoyl) cysteine. Food Chem Toxicol 1996; 34: 385-92.

52 Yu R, Mandlekar S, Harvey KJ, Ucker DS, Kong ANT. Chemopreventive isothiocyanates induce apoptosis and caspase-3-like protease activity. Cancer Res 1998; 58: 402-8.

53 Fimognari C, Lenzi M, Hrelia P. Chemoprevention of cancer by isothiocyanates and anthocyanins: mechanisms of action and structure-activity relationship. Curr Med Chem 2008; 15: 440-7.

54 Satyan KS, Swamy N, Dizon DS, Singh R, Granai CO, Brard L. Phenethyl isothiocyanate (PEITC) inhibits growth of ovarian cancer cells by inducing apoptosis: role of caspase and MAPK activation. Gynecol Oncol 2006; 103: 261-70.

55 Trachootham D, Zhou Y, Zhang H, Demizu Y, Chen Z, Pelicano H, et al. Selective killing of oncogenically transformed cells through a ROS-mediated mechanism by $\beta$-phenylethyl isothiocyanate. Cancer Cell 2006; 10: 241-52.

56 Trachootham D, Zhang H, Zhang W, Feng L, Du M, Zhou Y, et al. Effective elimination of fludarabine-resistant CLL cells by PEITC through a redox-mediated mechanism. Blood 2008; 112: 1912-22.

$57 \mathrm{Xu} \mathrm{K}$, Thornalley PJ. Involvement of GSH metabolism in the cytotoxicity of the phenethyl isothiocyanate and its cysteine conjugate to human leukaemia cells in vitro. Biochem Pharmacol 2001; 61: 165-77.

58 Hasegawa $\mathrm{T}$, Nishino $\mathrm{H}$, Iwashima $\mathrm{A}$. Isothiocyanates inhibit cell cycle progression of $\mathrm{HeLa}$ cells at $\mathrm{G}_{2} / \mathrm{M}$ phase. Anticancer Drugs 1993; 4: 273-9.

59 Matsui TA, Murata H, Sakabe T, Sowa Y, Horie N, Nakanishi R, et al. Sulforaphane induces cell cycle arrest and apoptosis in murine osteosarcoma cells in vitro and inhibits tumor growth in vivo. Oncol Rep 2007; 18: 1263-8.

60 Liang H, Lai B, Yuan Q. Sulforaphane induces cell-cycle arrest 
and apoptosis in cultured human lung adenocarcinoma LTEP-A2 cells and retards growth of LTEP-A2 xenografts in vivo. J Nat Prod 2008; 71: 1911-4.

61 Zhang YS, Tang L, Gonzalez V. Selected isothiocyanates rapidly induce growth inhibition of cancer cells. Mol Cancer Ther 2003; 2: 1045-52.

62 Xiao D, Srivastava SK, Lew KL, Zeng Y, Hershberger P, Johnson $\mathrm{CS}$, et al. Allyl isothiocyanate, a constituent of cruciferous vegetables, inhibits proliferation of human prostate cancer cells by causing $\mathrm{G}_{2} / \mathrm{M}$ arrest and inducing apoptosis. Carcinogenesis 2003; 24: 891-7.

63 Miyoshi N, Uchida K, Osawa T, Nakamura Y. Benzyl isothiocyanate modifies expression of the $\mathrm{G}_{2} / \mathrm{M}$ arrest-related genes. BioFactors 2004; 21: 23-6.

64 Zhang RF, Loganathan S, Humphreys I, Srivastava SK. Benzyl isothiocyanate-induced DNA damage causes $\mathrm{G}_{2} / \mathrm{M}$ cell cycle arrest and apoptosis in human pancreatic cancer cells. J Nutr 2006; 136: 2728-34.

65 Xiao D, Singh SV. Phenethyl isothiocyanate inhibits angiogenesis in vitro and ex vivo. Cancer Res 2007; 67: 2239-46.

66 Dashwood RH, Ho E. Dietary agents as histone deacetylase inhibitors: sulforaphane and structurally related isothiocyanates. Nutr Rev 2008; 66 Suppl 1: S36-8.

67 Myzak MC, Karplus PA, Chung FL, Dashwood RH. A novel mechanism of chemoprotection by sulforaphane: inhibition of histone deacetylase. Cancer Res 2004; 64: 5767-74.

68 Pledgie-Tracy A, Sobolewski MD, Davidson NE. Sulforaphane induces cell type-specific apoptosis in human breast cancer cell lines. Mol Cancer Ther 2007; 6: 1013-21.

69 Ma X, Fang Y, Beklemisheva A, Dal W, Feng J, Ahmed T, et al. Phenylhexyl isothiocyanate inhibits histone deacetylases and remodels chromatins to induce growth arrest in human leukaemia cells. Int J Oncol 2006; 28: 1287-93.

$70 \mathrm{Hu}$ J, Straub J, Xiao D, Singh SV, Yang HS, Sonenberg N, et al. Phenethyl isothiocyanate, a cancer chemopreventive constituent of cruciferous vegetables, inhibit cap-dependent translation by regulating the level and phosphorylation of 4E-BP1. Cancer Res 2007; 67: 3569-73. 